\title{
Laboreal
}

Volume $16 \mathrm{~N}^{\circ} 2$ | 2020

Programa de Pesquisa do Curso da Ação

\section{Conceção de formações que facilitem o surgimento de novos significados face a acontecimentos inéditos e críticos}

Diseñar formaciones que faciliten el surgimiento de nuevas significaciones frente a acontecimientos inéditos y críticos

Concevoir des formations facilitant l'émergence de nouvelles significations face à des évènements inédits et critiques

Training design fostering the emergence of new meanings toward unprecedented and critical events

Simon Flandin, Deli Salini, Artemis Drakos y Germain Poizat

\section{OpenEdition}

\section{Journals}

Edición electrónica

URL: http://journals.openedition.org/laboreal/17042

DOI: $10.4000 /$ laboreal. 17042

ISSN: 1646-5237

Editor

Universidade do Porto

Referencia electrónica

Simon Flandin, Deli Salini, Artemis Drakos y Germain Poizat, « Conceção de formações que facilitem o surgimento de novos significados face a acontecimentos inéditos e críticos ", Laboreal [En línea], Volume 16 No2 | 2020, Publicado el 01 diciembre 2020, consultado el 14 diciembre 2020. URL : http:// journals.openedition.org/laboreal/17042; DOI : https://doi.org/10.4000/laboreal.17042

Este documento fue generado automáticamente el 14 diciembre 2020.

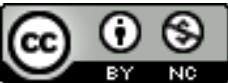

Laboreal está licenciado com uma Licença Creative Commons - Atribuição-NãoComercial 4.0 Internacional. 


\section{Conceção de formações que facilitem o surgimento de novos significados face a acontecimentos inéditos e críticos}

Diseñar formaciones que faciliten el surgimiento de nuevas significaciones frente a acontecimientos inéditos y críticos

Concevoir des formations facilitant l'émergence de nouvelles significations face à des évènements inédits et critiques

Training design fostering the emergence of new meanings toward unprecedented and critical events

Simon Flandin, Deli Salini, Artemis Drakos y Germain Poizat

\section{NOTA DEL EDITOR}

Manuscrito recibido en : 09/03/2020

Aceptado tras peritaje en : 26/10/2020

Traducción : Agustina Blanco [agustinablanco@gmail.com]

Esta investigación fue en parte financiada por la Fondation pour une Culture de Sécurité Industrielle (FONCSI - Fundación para una Cultura de la Seguridad Industrial) en el marco del proyecto FOResilience - Transformaciones de actividades y organizaciones para la seguridad industrial - hacia propuestas de formación a y para la resilencia (Contrato $n^{\circ}$ A0-2017-02).

Los autores agradecen Oriane Sitte de Longueval y Cyrille Gaudin por sus revisiones constructivas de las versiones provisorias de este artículo. 


\section{Pensar la formación según el enfoque del Curso de acción}

1 El programa de investigación curso de acción (CdA) (Theureau, 2006, 2009, 2015) constituye una matriz común a numerosas investigaciones en diversos campos de práctica, como muestra este dossier especial. Tales investigaciones pueden tener dos orientaciones, no excluyentes entre sí: una empírica (donde está en juego la comprensión), la otra tecnológica (donde está en juego el diseño). Las investigaciones tecnológicas tienen la particularidad de desear prioritariamente describir y provocar dinámicas de transformación de la actividad (potenciales, actuales y virtuales), a efectos de diseñar entornos socio-técnico-organizacionales, culturales y educativos. Las investigaciones empíricas, por su parte, buscan documentar y modelizar regularidades de la actividad descrita así "por sí misma". Ese trabajo de ordenamiento de la dimensión empírica muy a menudo conforma una etapa para las investigaciones tecnológicas que redundan en la concepción de dispositivos, en particular, en el ámbito de la educación y la formación. De este modo, han contribuido a validar, enriquecer y completar el programa genérico del $\mathrm{CdA}$, tanto desde un punto de vista teórico como metodológico (p. ej., Poizat, Durand, \& Theureau, 2016).

2 En el campo de la formación de adultos, en particular en el transcurso de la última década, el programa de investigación tecnológica (Durand, 2008; Poizat, \& Durand, 2015) ha elaborado principios de diseño de situaciones (i) de "videoformación", (ii) de simulación en formación, (iii) de formación de formadores y también (iv) de formación con mediación artística. Desde la primera sistematización de ese programa propuesta por Durand (2008), se han realizado numerosos avances. Estos se traducen en un progresivo cúmulo de hipótesis ontológicas adicionales, sobre todo en torno a la individuación-apropiación (p. ej., Poizat \& Goudeaux, 2014) o a la mímesis (p. ej., Durand, Goudeaux, Horcik, Salini, Danielian, \& Frobert, 2013), por medio de la formulación de distintos postulados no triviales acerca de la transformación de la actividad (p. ej., Durand, 2017) y por medio de una "concreción" cada vez más fuerte de las proposiciones de diseño y los razonamientos y métodos asociados (Poizat \& Flandin, en prensa [1]).

Dentro de ese marco, la presente contribución se interesa por las modalidades de construcción de significaciones nuevas durante, después o en vista de acontecimientos inéditos o críticos. Esta aprehensión de lo inédito y lo crítico en el área de la formación (i) es de suma importancia en diversos ámbitos de prácticas en los cuales predominan, por ejemplo, los desafíos relativos a la salud (p. ej., públicos en situaciones de vulnerabilidad) y a la seguridad (p. ej., industrias riesgosas) y (ii) es central desde una perspectiva "no curricular" (Flandin, Poizat, \& Perinet, 2019), orientada al desarrollo, como en el caso de las formaciones basadas en la mediación artística o la simulación de crisis (ejemplos en los cuales nos basamos en este artículo).

Comenzamos describiendo las contribuciones y consecuencias de la adopción de la hipótesis de la actividad-signo (Theureau, 2006) para la formación y por los avances y especulaciones en torno a la noción de abducción (Peirce, 1994); a partir de allí, conceptualizamos la noción de impasse (Salini \& Durand, 2020; Salini \& Poizat, en impresión). Nos fundamos después en el análisis -paralelo, luego convergente- de dos dispositivos que pueden ser considerados prototípicos de formaciones "reparadoras" de una vivencia de impasse (Théâtre du Vécu, Teatro de la Vivencia) y "preparadoras" para 
una vivencia de impasse (ejercicio de crisis). Proseguimos con la enunciación de los principios de diseño derivados de ese análisis empírico. La discusión final del presente artículo contribuye a un programa de investigación en materia de formación de adultos y a las nuevas perspectivas de investigación que de allí emanan.

\subsection{Interés y consecuencias de la hipótesis de la actividad-signo en el campo de la formación}

5 Las consecuencias de las hipótesis ontológicas de la enacción y de la experiencia (véase el artículo introductorio a este dossier especial) han sido ampliamente tratadas en las síntesis existentes sobre el desarrollo del programa CdA en educación y formación (p. ej., Poizat, Salini, \& Durand, 2013). Asimismo, la hipótesis analítica de la actividad-signo ha sido muy utilizada en las investigaciones en el área educativa para describir y modelizar fenómenos, dinámicas y trayectorias de aprendizaje-desarrollo (Durand, 2008), apropiación, descubrimiento y creación. En cambio, a nuestro parecer, su "potencial tecnológico" está insuficientemente explorado, sobre todo su fecundidad para comprender las condiciones favorables a ciertas transformaciones mejoradoras de la actividad y para diseñar situaciones de formación.

6 La hipótesis de la actividad-signo fue planteada por Theureau (2006) a partir de la conjunción de la hipótesis de la enacción de Maturana y Varela (1994) y aquella del pensamiento-signo de Peirce (1994), partiendo del postulado de que actividad y cognición son indisociables. Si toda actividad es cognitiva, y toda cognición está inscrita en una semiosis -dicho de otro modo, en una dinámica de significación-, entonces toda dinámica de actividad es una actividad-signo (Theureau, 2006). Esta hipótesis permite articular una fenomenología empírica de la actividad humana y una teoría generalizada de la significación y abre el camino a un sistema de nociones descriptivas y explicativas que constituye el marco de análisis semiológico de la actividad humana (Theureau, $2006,2009,2015)$. Asimismo, se refiere a la experiencia vivida del actor y a priori no separa pensar, actuar, sentir, vivenciar, experimentar, saber, etc. : los contenidos de las experiencias son enactuados por el actor "paso a paso", o para ser más exactos, "de signo en signo". Si toda actividad es cognitiva y a su vez significante, en toda situación experimentada por un individuo se ponen en funcionamiento dinámicas de transformación de las significaciones, las cuales reconfiguran permanentemente, y de manera más o menos importante, los saberes y los nexos entre los saberes del actor.

7 Así, las "experiencias de saberes" (Dieumegard, 2011) de diversa índole (saber hacer, conocimiento, saberes simbólicos, saberes no simbólicos, etc.) se van conformando en el curso de la actividad y son consideradas interpretaciones inherentes a la situación que el actor genera (Dieumegard, 2009). El aprendizaje está documentado por la construcción de prototipos, tipos y relaciones entre tipos (Rosch, 1973). Aprender consiste para el actor en tipicalizar o tipificar [2] correlaciones con la situación (incluyendo otros actores). Esos tipos pueden ser más o menos consensuales en el seno de una comunidad y/o ser elaborados de manera colectiva a través de una construcción de sentido participativa. Constituyen luego anclajes en la aprehensión de los acontecimientos y las acciones (Schütz, 1987). Un pájaro que un individuo distingue en un bosque es identificado o categorizado en el curso de la acción por medio de juicios de proximidad o de distancia dentro del tipo, o redes de tipos relativos a una identidad "pájaro" (forma, color, sonido del trino, atributos del bosque, etc.), que son propias de ese 
individuo. Pero este proceso se pone en marcha sean cuales fueren las formas de acción. Al realizar una manipulación, un fisioterapeuta tipicaliza en cada instante su experiencia y las reacciones del paciente y entabla una acción sobre la base de juicios de tipicalidad. En situaciones muy complejas, esos tipos se articulan y resultan en configuraciones (o reconfiguraciones) de tipos igualmente muy complejos y difíciles de describir localmente.

8 Según este enfoque, los aprendizajes no se realizan, pues, según un modo secuencial, por acumulación "mecánica" de elementos nuevos dentro de una base disponible, sino que se expresan mediante el surgimiento de una novedad, en un contexto de reconfiguración de lo que ya está. Por lo tanto, la actividad es, en simultáneo o iterativamente, conservación y reproducción, pero también surgimiento y transformación que hacen posible la invención y la creación. Detallada más adelante, la noción de Interpretante, que se inscribe en el marco del análisis semiológico de la actividad elaborado por Theureau (p. ej. 2006) a partir de la semiótica de Peirce, permite dar cuenta de ese principio con precisión. Desde esa perspectiva, la formación tiene un doble propósito : favorecer ese proceso de creación de la novedad sobre un fondo de reconfiguración del presente y buscar convertirla "mejoradora", es decir, apta para transformar la actividad de forma deseable desde el punto de vista de los actores y los formadores. Esta perspectiva no se basa entonces en la "clásica" especificación de una lista de objetivos pedagógicos precisos, comúnmente enunciados del siguiente modo: "Al cabo de la formación, los participantes serán capaces de...". El carácter mejorador radica en el incremento esperado de una capacidad "global" de los actores para experimentar y actuar en tipos de situaciones tendencialmente difíciles. En los dispositivos aquí presentados, la mejora se concreta mediante la superación de vivencias de impasse.

\subsection{Interpretante, signo hexádico y abducción}

9 La noción de Interpretante (I), movilizada en el marco teórico semiológico del CdA, se inspira en aquella desarrollada por Peirce, quien, a través de esa categoría, inscribe tanto la implementación de los saberes adquiridos como la creación de saberes nuevos dentro del signo. Tal implementación se introduce dentro del conjunto de la semiosis, que para Peirce se constituye en la interacción triádica [3] entre tres categorías de la experiencia : lo "Posible", que remite a propensiones que podrían o no actualizarse en una situación ; lo "Actual", que remite a las percepciones y reacciones significativas y específicas de y dentro de lo real; lo "Virtual", que remite a la generalización emergente de la interacción entre las categorías anteriores, lo cual anula o modifica significaciones previamente constituidas. A partir de tal categorización, Theureau (2006) elabora la noción de signo hexádico [4], una matriz con seis componentes, cada uno de los cuales está dinámicamente ligado a los demás (Cuadro 1). El signo hexádico posibilita la descripción del curso de experiencia, es decir, un nivel de reducción de la actividad que toma en consideración aquello que es significativo para el actor, mostrable, narrable, imitable y comentable por este, según condiciones éticas y metodológicas particulares. 
Cuadro 1 : Los seis componentes de las tres categorias de experiencia

\begin{tabular}{l}
\begin{tabular}{l} 
Posible \\
$\begin{array}{l}\text { Compromiso (E): intenciones, preocupaciones, estados afectivos, } \\
\text { abiertos de investigación }\end{array}$ \\
$\begin{array}{l}\text { Anticipación (A): expectativas o anticipaciones y previsiones de acción } \\
\text { en las sucesivas unidades }\end{array}$ \\
$\begin{array}{l}\text { Referencial (S): tipos, relaciones entre tipos y principios de } \\
\text { interpretación pertenecientes a la cultura del actor, que este puede } \\
\text { movilizar habida cuenta de (E) y (A) en un momento dado }\end{array}$ \\
\hline $\begin{array}{l}\text { Representamen (R): aquello que constituye un signo para el actor en } \\
\text { un momento dado }\end{array}$ \\
\hline Actual
\end{tabular} $\begin{array}{l}\text { Unidad de curso de experiencia(U): acciones prácticas, discursos } \\
\text { privados, comunicaciones y emociones actualizadas }\end{array}$ \\
\hline Table 1: The six components of the three categories of experience. \\
\hline Virtual
\end{tabular}

Cuadro 1 : Los seis componentes de las tres categorias de experiencia

La categoría del Interpretante se refiere a la "transformación" (creación, incorporación y/o reorganización) que se aporta al Referencial (es decir, a los tipos y relaciones entre tipos disponibles para el actor) en el decurso de la actividad, poniendo de manifiesto la constante conversión, en grados diversos, del saber del actor, de sus hábitos situados (o de sus tipificaciones), y por tanto de su cultura propia.

11 Según Peirce (1868), comprender las transformaciones expresadas por el Interpretante, y sobre todo cómo conseguimos conocer algo que no sabemos a partir de algo que sí sabemos, pasa por captar el rol de las inferencias en la semiosis. Para el autor, carecemos de un poder de intuición y, por ende, nos resulta imposible tener una aprehensión inmediata de lo real, aunque cada acto de conocimiento procede por inferencia de un conocimiento anterior. Esta hipótesis no excluye el descubrimiento, pero conduce a contemplarlo como resultado de un caso particular de inferencia: la abducción. Esta se añade a dos inferencias más conocidas: la deducción, que es la aplicación de una regla general a casos particulares (que tiene así una función explicativa o de justificación) y la inducción, que es una derivación de una regla desde uno o varios casos y un resultado (que tiene así una función de comprobación o de generalización horizontal). La abducción consiste en la inferencia de un caso desde una regla y un resultado, o más precisamente, el surgimiento al mismo tiempo de una regla en relación con un caso que le da una "razón" (Peirce, 1868).

12 Con la abducción, el grado de novedad (o al menos de novedad percibida por el actor) es ampliamente superior a aquel de la deducción o de la inducción. Activada a partir de un hecho sorprendente o "inesperado" que contradice anticipaciones previas (Salini, 2013), la abducción no genera certeza, pero hace emerger una hipótesis provisoria (para la acción) y la predicción de una posibilidad en tanto opción entre otras posibles, 
proponiendo una nueva forma de relación entre elementos desconocidos, a partir de elementos conocidos. Se trata de una hipótesis que surge, o se enacta, como tentativa de comprensión de las "posibles causas" de algún hecho observado, cuyas "verdaderas causas" son desconocidas. La abducción se emparenta entonces con una forma "de analogía aventurada atípica" (Theureau, 2015).

En los procesos abductivos, las dimensiones icónicas de la significación como hipótesis de comprensión desempeñan un papel esencial (Fisette, 2009; Peirce, 1994). Se expresan mediante el surgimiento de signos que remiten a su objeto por semejanza, fundándose en un conjunto de dimensiones corporales, sensoriales, emocionales o conceptuales. Estos signos icónicos (imágenes, diagramas y metáforas), si bien conservan su dimensión triádica, se refieren sobre todo a la experiencia de lo Posible. Tienen una dimensión vaga, inestable y abierta, sin contornos definidos, y constituyen hipótesis de interpretación del mundo y, en ese sentido, inferencias abductivas (Fisette, 2009). En particular, la metáfora propone un nuevo signo, más precisamente una generalización del vínculo entre dos signos, fundada en similitudes "inesperadas". Por una parte, expresa una hipótesis de regularidad acerca de un nexo específico entre dos signos, por otra, como toda generalización (aunque hipotética), configura la anticipación de las acciones y los sucesivos acontecimientos, otorgándoles cierta previsibilidad (Fisette, 2009 ; Salini, 2013).

modalidad de razonamiento abductiva es crucial en el surgimiento de nuevas significaciones, ya sea en situaciones ordinarias, ya sea cuando los actores o los colectivos hacen frente a sucesos sorprendentes, inéditos, anquilosantes y críticos. Poco estudiadas en el campo educativo, las inferencias abductivas, empero, son determinantes a la hora de comprender la transformación de la actividad individual y colectiva, pero también de idear, mejorar o evaluar ciertas situaciones o dispositivos de formación (Cunningham, 1998).

15 La pertinencia del estudio de las modalidades de aprendizaje-desarrollo en términos de semiosis ya ha sido señalada en la literatura (Bopry, 2007, Colapietro et al., 2005; Midtgarden, 2005, 2010; Stables \& Gough, 2006) y, en particular, el aprendizaje por abducción (Cunningham, 1998; Paavola \& Hakkarainen, 2005 ; Ventimiglia, 2005). Según Cunningham, Schreiber y Moss (2005), la abducción es a menudo desatendida al momento de comprender el aprendizaje, en favor de la inducción y la deducción, que predominan en el pensamiento "tradicional" de la enseñanza : los docentes explican las reglas y la información útiles para los y las participantes, quienes luego las ponen a prueba a través de diversos ejercicios y resoluciones de problemas. En los dispositivos pedagógicos que apuntan a fomentar un razonamiento abductivo, los y las participantes son alentados/as más bien a observar e interpretar elementos asombrosos, lo cual estimula (en el campo escolar) la formulación de hipótesis explicativas y el desarrollo de un espíritu crítico (p. ej. Ahmed \& Parsons, 2013 ; Hwang, Hong, Ye, Wu, Tai, \& Kiu, 2019 ; Oh, 2011).

Contrariamente a las investigaciones de este tipo, que consideran que los "estudios abductivos" (Oh, 2008) tienen un interés intrínseco, nuestra investigación examina las condiciones (empíricas) en las cuales la abducción juega un rol de desarrollo determinante y las condiciones (tecnológicas) bajo las cuales los dispositivos de formación pueden provocar y propiciar ese proceso. El objeto del presente artículo no es solamente, pues, documentar la construcción de nuevas significaciones a través de la 
abducción, sino también utilizar mejor los procesos abductivos para idear situaciones de formación.

\subsection{Aproximación semiológica de lo "inesperado" y de las vivencias de impasse}

17 En la dinámica entre conocido y desconocido, la noción de "inesperado" es central, sobre todo si se considera la manera en que Peirce (1994) explica la idea de sorpresa. Esta última indica que aquello que aconteció contradice la regularidad esperada y hace emerger así la "ruptura de la expectativa de una regularidad". Al hacerlo, apunta hacia la posibilidad de otra regularidad. Lo "inesperado" es entonces algo que requiere un cambio en nuestros modos de significación, en nuestras generalizaciones antes constituidas, activando el movimiento de investigación y la posibilidad de constituir nuevos conocimientos (Peirce, 1994). Eso "inesperado" puede aparecer según diferentes grados de sorpresa, siguiendo distintos matices de "previsibilidad" hasta "aquello que no se puede prever" (Grossetti, 1994). Así pues, se puede diferenciar a los "inesperados", cuya realización es previsible pero cuyo momento de acaecimiento no lo es, de los "impensados", es decir, "inesperados" que jamás fueron imaginados, ni a fortiori descritos ni previstos.

La vivencia de impasse sucede cuando algo entorpece la continuidad del recorrido interpretativo que surge con motivo de una eventualidad inhabitual, cargada de un importante nivel de "inesperado" en la experiencia del actor. En ese caso, una parte de la dinámica global de significación no logra desembocar en generalizaciones establecidas y, de tal forma, termina retrayéndose sobre sí misma. Surge entonces un cuestionamiento sin respuestas, que puede ser compulsivo y generador de disposiciones afectivas negativas. La situación "inesperada" permanece incomprensible, inexpresable, no compartible, y lo que aconteció no es superado : a lo cual se asocia una molestia, un sufrimiento o una sensación de inconclusión. Esa vivencia de impasse muchas veces es calificada mediante metáforas como "callejón sin salida", lo cual remite a algo que impide avanzar o retroceder ; o como "girar en falso", lo cual da cuenta del hecho de que las cuestiones son reiterativas, que quedan sin respuesta o reciben respuestas poco convincentes (Salini \& Poizat, en prensa). Se trata de una dinámica que se repliega o que no abre hacia nada que no sea ella misma, un "nudo" que paraliza la actividad, ya que los distintos hilos se enmarañan sin posibilidad aparente de desenredarlos. La vivencia de impasse consta de una dimensión afectiva que está compuesta a su vez de inquietud (hasta la angustia) y de una obstaculización de la relación con lo/el colectivo (Simondon, 2005). Con diferentes niveles de intensidad, el individuo se siente desamparado, inseguro y preocupado, cuando no agobiado. A veces tal desamparo se torna crónico y deviene en un trasfondo permanente y pernicioso de la actividad. El sentimiento de soledad es considerable y a menudo va de la mano con sentir que no es posible darse a entender.

Con motivo de una vivencia de impasse, la semiosis -en tanto dinámica inscrita dentro de una temporalidad- sufre una suerte de cortocircuito : ya no hay apertura hacia un porvenir ni un devenir. Los individuos se desligan de su proceso de individuación, que pasa por circuitos largos (Stiegler, 2010), y tal desvinculación se efectúa ya sea por medio de una ruptura brutal de su relación con el mundo (experiencia disruptiva, estupefacción), ya sea por una vuelta continua a preguntas sempiternas (como un 
resorte roto, el pasado se ve invariablemente "presentificado", Violi, 2014). Esa traba en la proyección hacia el futuro puede ser entendida a la luz de la dimensión esencial de la experiencia de la temporalidad, y el marco de análisis semiológico del curso de experiencia permite describir el modo según el cual esa vivencia se inscribe en la dinámica de significación de un actor en un momento dado (Theureau, 2006). Lo anterior se funda en la hipótesis de que el contenido de lo que es expresable en un momento dado por un actor desborda la mera descripción de lo que acontece en ese momento, ya que siempre está vinculado con la actividad precedente y sucesiva. En ese sentido, Theureau (2006) subraya la dimensión dinámica y "abierta en ambos extremos" de la actividad, un flujo que en cada instante hereda la historia de la actividad pasada (concepto husserliano de "retención") y que se abre hacia el futuro (concepto husserliano de "protensión"). La relación entre protensión y retención es asimétrica en favor de la protensión: como el ser viviente es fundamentalmente normativo y como la actividad es su expresión, esta se orienta ante todo hacia el futuro inmediato (Husserl, 1964). En función de tales concepciones, podemos considerar el impasse como un bloqueo en la retención del pasado que paraliza la protensión hacia el futuro.

\section{Acompañar la reanudación de la semiosis y extender el entendimiento en la formación}

Los dos estudios que vamos a presentar permiten captar que, en la vivencia de impasse como repliegue o "desplome" (Weick, 1993) de la dinámica de significación [5], el movimiento abductivo posibilita una salida o un rebote. En el primer caso, analizaremos una formación con miras "reparadoras", que apunta a ayudar a los y las participantes a superar una vivencia de impasse y a volver a desplegar sus semiosis. En el segundo caso, analizaremos una formación con miras "preparadoras", en la cual la vivencia de impasse es producida "artificialmente", con el fin de ayudar a los y las participantes a prefigurarse, de forma controlada, una situación que podría producirse potencialmente en el futuro en un contexto real y de trabajar en consecuencia para extender el propio entendimiento de cada uno/a.

\subsection{Un prototipo de formación "reparadora" con mediación artística}

21 A modo de ejemplo de una formación con miras "reparadoras", presentamos el dispositivo Théâtre du vécu [Teatro de la Vivencia] (TdV) (Assal, Durand, \& Horn, 2016), dirigido a adultos con biografías marcadas por patologías graves o episodios dramáticos. Este dispositivo propone una elaboración por etapas de determinados acontecimientos de la experiencia de los y las participantes y su transformación en una forma teatral que le brinde una nueva significación. Se desmarca de una perspectiva de formación conocida como curricular y centrada en objetivos de aprendizaje y se inscribe en una tradición humanista de la educación que apunta al desarrollo de los adultos (Salini \& Durand, 2016).

El TdV consiste en el acompañamiento de cinco o seis participantes durante tres días a un espacio teatral, a cargo de profesionales de la educación de adultos, el cuidado y el teatro. Se solicita a los y las participantes: (i) que escriban un texto relativo a "un episodio importante de sus vidas", (ii) que lo pongan en escena y (iii) que dirijan a los 
actores hasta la realización del espectáculo delante de un público restringido. Cada fase del TdV se ve ritmada por "mesas redondas". Allí, los y las participantes dan testimonio de lo que están viviendo, comentan la experiencia de sus pares y contribuyen a una reflexividad compartida. El taller se desenvuelve dentro de una dinámica de apoyo y ayuda por parte de los profesionales intervinientes y de sostén mutuo y solidaridad entre participantes.

El estudio referido a este dispositivo se basó en la observación etnográfica de cinco talleres de TdV y en el registro en video de tres de ellos (Salini \& Durand, 2016). La actividad de 18 participantes fue analizada de manera pormenorizada a partir de observaciones in situ y sesiones de autoconfrontación (AC) con base en las trazas de esos talleres (resúmenes de video, notas de campo) (Theureau, 2010). Esas sesiones [ $\left.{ }^{6}\right]$, también grabadas, facilitaban la expresión de la experiencia, es decir la dimensión mostrable, narrable, imitable y comentable en todo momento de la actividad (Theureau, 2010). Durante esas sesiones, los actores seguían el desarrollo de su actividad pasada reflejada en el video, para expresar su experiencia en ese momento, evitando explicaciones, generalizaciones y justificaciones. Esos datos fueron completados por entre una y tres entrevistas posteriores al TdV, en el domicilio de los y las participantes, con intervalos de tres meses a dos años.

El procesamiento de los datos consistió en un análisis semiológico de la experiencia de los actores involucrados, sobre la base del signo hexádico. Los elementos expresados por cada uno fueron primero organizados en crónicas individuales, estructuradas según la temporalidad y las actividades específicas de la trama del TdV, luego examinados según el marco de análisis semiológico presentado con anterioridad (Theureau, 2006). El procesamiento final apuntaba a identificar componentes de la experiencia evaluados como típicos en los niveles individual e interindividual. Los juicios de tipicidad se plantearon a partir de los criterios de frecuencia de incidencia en la muestra investigada y de aquellos emitidos por los actores durante las AC.

Los resultados del estudio permiten abarcar los múltiples elementos que coadyuvan al desenlace de ciertas vivencias de impasse de los y las participantes. Estos serán presentados basándose muy puntualmente en la experiencia de Julia, que asistió a los talleres en 2013. Los investigadores se reunieron con ella en dos ocasiones : en el marco de la AC a la semana siguiente al taller y seis meses después.

\subsubsection{No soy un héroe}

Julia [ $\left.{ }^{7}\right]$ es una auxiliar de enfermería experimentada que, durante el taller, desea desentrañar una situación muy compleja ligada a los días en que se vio confrontada a la tentativa de suicidio de la madre de un niño al que ella atendía, así como a las críticas de sus colegas por su supuesto "exceso de involucramiento". Su vivencia de impasse concierne tanto lo que para ella es "impensable", es decir, el gesto de aquella madre, como la imposibilidad de salir del cuestionamiento respecto de su forma de actuar y de comprometerse de manera importante con esa madre. Julia alude a su dilema en su texto inicial, del cual reproducimos a continuación algunos fragmentos.

"No soy un héroe 
Salgo de su cuarto, estoy conmovida (...) Lo primero que me preguntó fue : ‘'y los niños ?' Le hablo, le hablo. Su mirada es franca y comienzan a brotarle lágrimas. Lloro con ella y, mientras se seca las lágrimas, le digo y vuelvo a decir : 'Realmente lo siento' (...)

Somos un equipo que estamos apoyando a esta familia desde hace dos años. Se hizo todo lo posible por el cuidado de su hijo. (...) Pero procuro no juzgarla...

Y ahí vienen las frases fatídicas de los colegas, que odio : 'Ten cuidado, protégete, ¿no estarás exagerando ?'. ¡Cómo me irritan! (...). Asimismo, pienso en mí, que no puedo entender que se pueda perder la esperanza. (...)

Más tarde, le digo que si no murió es porque no era el momento, que aún le quedan cosas por hacer... En ese instante estallamos de risa, su risa es un regalo que me hace, me dice gracias porque, aunque yo no entienda su acto, no la juzgo (...)."

\subsubsection{Desenlace de la impasse y reanudación de la semiosis}

Transcribimos aquí algunos momentos claves de la experiencia de Julia durante el $\mathrm{TdV}$, documentados durante la entrevista de AC que siguió. También mencionamos los principales componentes del signo hexádico identificados.

Como indicamos anteriormente, en el marco del taller el Compromiso (E) de Julia respondía a la posibilidad de desentrañar, entender mejor y darse a entender en relación con sentimientos múltiples que la atravesaban a raíz de esa situación difícil que había escogido. Julia se involucra en el taller (el cual le fue propuesto por un médico conocido) confiada, pero también dubitativa en cuanto al modo de proceder. La atmósfera que ofrecen los profesionales intervinientes la interpela (R) de manera positiva y así lo interpreta ella (I): "Es un trabajo inteligente para ponernos cómodos, realmente me sentí cómoda muy rápido y enseguida me hicieron sentir segura". El recibimiento $(\mathrm{R})$ por parte de los demás participantes la conmueve, pues a través de pequeños gestos le hacen sentir que están allí, presentes aunque silenciosos: "un momento que todavía me emociona fue cuando uno de los participantes sólo apoyó su mano sobre mi hombro y me dijo : vamos, estás en tu derecho".

Como a la mayoría de ellos, a Julia la escritura le resulta más fácil de lo previsto : "Yo pensaba : ¿cómo me irá ? (U/I) (...). Estoy sorprendida porque me esperaba que fuera difícil para mí (A). Pero no, la cosa cae por su propio peso". La tarde del primer día, oír la lectura de los textos de los otros también es emotivo, "te saca de tu historia y te transporta hacia situaciones (I). Intento comprender que está viviendo cada uno (E) y me interesan mucho los otros textos (R)". De igual modo, la lectura neutra por parte de los actores profesionales abre la vía a una experiencia muy distinta : "Sobre todo, tomas distancia. Piensas : hay otro que lo está contando (R), es como si uno observara la situación, como si flotaras un poco" (I).

Durante la lectura, así como a lo largo de la realización de la obra, advertimos una preocupación relativa a la calidad y a la fidelidad del texto : ¿ ¿Soy lo suficientemente fiel a lo que sucedió de veras? (E). Y observo: está bien, está bien lo que dije (I). Es como una verificación : bueno, no dijiste tantas tonterías (I)". Durante la puesta en escena, también existe la inquietud en cuanto a cómo proceder (I/U). En ese momento, el apoyo del director teatral es crucial : acompaña y sugiere, al tiempo que habilita una libertad de elección : "sus preguntas : ‘es realmente así? ¿quieres otro color? ¿atenuar la luz?' Todas esas 
preguntas me hacen sentir que me está dando permiso para cuidar mi puesta en escena". La cuestión de la fidelidad es recurrente. Por ejemplo, cuando un actor dice una cosa muy dramática (R) "pienso que no se parece a la escena (U)... pienso que me importa que sea fiel a lo que sentí en la situación (E)". La preocupación estética está muy presente también, ya que para Julia la obra debe también conservar una dimensión de belleza (E).

En el transcurso de la elaboración, la obra "dialoga" con su autor y también propone posibilidades de comprensión y lectura inéditas para la gente allegada "que importa" (Salini \& Durand, 2016). Y de golpe Julia piensa, durante la proyección de su obra finalizada : "mi colega tiene que ver esto. (A) Tiene que poder ver qué ocurrió. Y que ambas podamos charlarlo(E)". Esto en realidad sucederá y finalmente Julia se siente comprendida por su colega: "Cuando pudo verlo, dijo: 'Gracias. Ahora entiendo. Nunca me atreví a decirte mis sentimientos contradictorios, tú también los tenías y por tontas no los compartimos"'. El taller también tuvo para Julia un efecto esclarecedor y confirmatorio de sus valores : "El hecho de haberlo planteado (el episodio evocado) lo coloca en relación con mis valores y está OK conmigo (I)". Por otra parte, se siente mejor respecto de su vínculo con la paciente recordada, así como con otros pacientes igual de complejos: "Cuando los veo, mi actitud es más serena (I). Ya no me siento fagocitada por esos pensamientos. Siento una especie de calma, de serenidad (E)". También recalca el encuentro consigo misma, en virtud del conocimiento de sí y de la apertura de un potencial que vale para el futuro: "me conozco mejor y veo que soy como los demás (I)".

Gracias al TdV, la dificultad inicial y la vivencia de sufrimiento son "re-presentadas" en tanto acontecimiento sobresaliente en el texto-relato redactado el primer día del taller. Se trata de textos simples, que van al grano, pero su redacción permite dar una organización y una consistencia a esa vivencia, adoptando un esquema narrativo e iniciando a su vez su exteriorización.

33 La elaboración de la obra es una ocasión para "retroceder" hasta la situación que origina la propia dificultad, abriendo hacia un futuro por medio de un trabajo de metaforización. La totalidad de la puesta en escena evoca de manera icónica las distintas facetas de la vivencia de Julia y su posible desenlace. A través de la voz de los actores, ella va narrando sus dudas, sus contradicciones, sus angustias y sus cuestionamientos. Las emociones vividas regresan entonces como "capturadas desde el exterior", y Julia experimenta en simultáneo el ser autora y espectadora de su obra. En ese juego de compromisos múltiples, se produce una experiencia transicional compleja : de una preocupación a otra, de una emoción a otra, de una significación a otra. Los momentos de intercambio que se suceden a cada momento clave del taller y las mencionadas "mesas redondas" permiten a Julia compartir sus inquietudes. Gracias a la obra, los y las demás participantes sintieron su vivencia, pero además captaron sus valores esenciales. Su experiencia individual se transforma mediante ese trabajo en presencia del otro, así como mediante la escucha y el acompañamiento de todos.

34 En términos más generales, en el TdV, la mediación de la experiencia-meta (la vivencia agobiante) se ve posibilitada por la amplificación de la actividad imaginativa y por el encastre de varios elementos de índole ficcional (Salini \& Durand, 2016). Tales elementos pueden sostener el diseño de dispositivos de formación con mediación artística, que sintetizamos como sigue :

- El registro mimético. Gracias a la producción de la obra, los y las participantes entran en resonancia con sus vivencias y, a su vez, con las vivencias de otros (Gallese, 2011) ; 
- El registro del "vagar" [8] (Peirce, 1994). La propuesta teatral permite que los y las participantes se liberen de una finalización estrecha de la acción y posibiliten la divagación : se confía en la imaginación, donde la diversión y la risa no son escandalosas ni sinónimo de tiempo perdido ;

- El registro de la metaforización. El texto inicialmente producido, que siempre es la referencia para la elaboración escénica, se transforma en tridimensional y se enriquece a lo largo de todo el taller con posibilidades de expresión inéditas, gracias a la omnipresencia de las metáforas. Estas son convencionales y culturales. Facilitan la comprensión del meollo de la cuestión por parte del espectador, dado que la puesta en escena "dice" a cada instante : "esto es una puesta en escena de aquello". Tales metáforas desembocan en un posible desenlace del suceso (en el sentido propio de deshacer un nudo) que constituye el objeto de la teatralización. La progresiva conformación de la obra teatral abre así la posibilidad de ver situaciones que permanecieron "en suspenso", hallar su epílogo y recomponer de forma imaginaria ausencias y vacíos en los intercambios vividos ;

- El registro de la participación metaléptica (Genette, 2004). Como se desprende de la experiencia de Julia, cada participante expresa diversos compromisos simultáneos o sucesivos en atención a su texto y a su producción teatral : (i) como testigo en primera persona e intérprete de su experiencia, (ii) como autor de un texto que lo concierne, (iii) como responsable de la puesta en escena de ese texto, (iv) como espectador-comentador y analista de su propio espectáculo, (v) como espectador-comentador y analista del espectáculo de los otros y, por último, (vi) como aprendiz del proceso de puesta en escena y dirección de actores. Esas diferentes posturas son fuente de intrusiones y desajustes durante el taller, suscitando rupturas y colisiones que propician una relación cambiante con la obra en curso y con las experiencias personales ;

- La externalización del diálogo interno (Rosenthal, 2012). La dinámica de significación es "intrínsecamente social, en el sentido de que se dirige a un interlocutor al menos virtual" (Chauviré, 2016, p. 118). La dimensión teatral del TdV, especialmente a través de la creación de personajes y alter egos, concreta y exterioriza el diálogo interno (Peirce, 1994), así como las dudas, contradicciones e hipótesis que los atraviesan. Esto permite que los y las participantes vean esto desde afuera, teniendo así la posibilidad de volver a aprehenderlo de cero.

\subsection{Un prototipo de formación "preparadora" : el ejercicio de crisis "fuera de cuadro"}

Considerado desde la perspectiva de la formación, el segundo dispositivo estudiado es un ejercicio de crisis "fuera del cuadro", es decir, que simula un acontecimiento totalmente inédito y analizado como prototipo de formación con miras "preparadoras". Busca ayudar a los individuos involucrados a desarrollar disposiciones para "ver", "percibir", "sentir", "actuar", "imaginar", "interactuar" en situaciones futuras, las cuales, en su defecto, son susceptibles de ser vividas como críticas y de aminorar, y hasta aniquilar, la capacidad de atención, interpretación y acción (estrés, incertidumbre, desplome de la semiosis, etc.), en particular dentro de contextos riesgosos (en este caso, la seguridad industrial). El ejercicio "fuera del cuadro" consiste en escenificar acontecimientos "inesperados" pero también "impensados" y aspira a que los individuos experimenten de forma controlado las situaciones provocadas y la vivencia de impasse asociada a éstas. 
Este estudio se origina en el proyecto FOResilience [ $\left.{ }^{9}\right]$, que trata de la formación en y por la resiliencia en el campo de la seguridad industrial. Nuestro análisis se detiene primero en el comportamiento de un actor-clave primer-interviniente (el agente de conducción a cargo, instalado en el pupitre de supervisión) en el transcurso de un ejercicio de crisis a gran escala, organizado en una planta de almacenamiento de gas. Los datos de este estudio se construyeron a partir de una observación etnográfica y de una entrevista consecutiva con ese actor, siguiendo el método de verbalización desfasada (Theureau, 2010). Con ayuda del signo hexádico, damos cuenta de la superación por abducción de una vivencia de impasse y luego presentamos las oportunidades de desarrollo que propicia la confrontación con un suceso que se revela no sólo "inesperado" sino también "impensado".

\subsection{1 "iNi se les ocurra hacerme eso !"}

El caso aquí presentado es particularmente interesante por uno de los elementos de su guion, ideado para desconcertar a los operarios: la simulación de la muerte de dos agentes de guardia. En el transcurso del ejercicio, el acontecimiento se produce como sigue: alertado acerca de una anomalía en un conducto de gas (R), el agente de conducción aplica el procedimiento (S), contactando a los agentes de guardia para solicitarles que "despejen dudas" in situ (U/S). Minutos más tarde, estos agentes fallecen de modo ficticio cuando explota el conducto, pero tal como estaba previsto en el guion, ningún ni ninguna participante está presente en el lugar para dar cuenta de ello. El moderador del ejercicio coloca a los dos agentes de guardia fuera del ejercicio y sólo informa a los demás operarios, entre ellos, el agente de conducción, de que se ha oído una explosión de fuerte intensidad en la zona (R).

La actividad del agente de conducción, primer-interviniente $\mathrm{y}$, en ese instante, principal actor de la gestión de crisis, se ve entonces perturbada dentro del campo de lo "inesperado", ya que las explosiones son muy infrecuentes (S) aunque posibles (S). Aplica entonces el procedimiento previsto (S) contactando a los bomberos (U). La perturbación se mueve al campo de lo "impensado" cuando busca contactar por teléfono a los dos agentes de guardia (E). Tras intentarlo en vano cuatro veces (U/R) siendo que el guardia tiene la obligación terminante de responder a las llamadas (S)- se ve invadido por la incomprensión y por un manifiesto estrés (I) que traduce verbalmente (U) por la frase : "ii ¿No lo puedo creer?!!" (I) (7:01 y $7: 05$ horas) [ ${ }^{10}$ ], “¡Pero llámame!" (U) (7:06 horas), “¡No puede ser!” (I) (7:07 horas), "No vamos a lograrlo..." (I) (7:09 horas).

Las hipótesis de una deficiencia técnica del sistema de comunicación (I) o de un desliz en el procedimiento por parte del guardia (I) le parecen totalmente improbables (I). Emite entonces una hipótesis que le resulta plausible (I) : una falla en el guion del ejercicio. En efecto, estima que no es posible que el guardia no responda al teléfono (I), inclusive habiendo sido informado de la explosión (S). Pero el moderador le confirma el correcto desenvolvimiento del guion (R), lo cual lo mantiene en su estado de estrés y perplejidad (R/I).

40 Comienza a buscar entonces cómo proseguir su acción en esa situación inédita (E), por más que eso implique apartarse del procedimiento (I) (despejar dudas por parte del guardia) y aceptar al menos momentáneamente su estado de incertidumbre (I). Desiste de volver a contactar al guardia $(\mathrm{U})$ y decide contactar a otro agente de mantenimiento 
(U) que se hallare a proximidad de la zona del siniestro. Consulta la planeación dinámica de las operaciones (U), que indica con gran precisión y buena legibilidad dónde están y qué están haciendo los operarios en cada momento (S). Identifica a un agente (R) y lo contacta para pedirle que acuda al lugar (U). Un aspecto relativo a la seguridad surge entonces en su campo de preocupación (E), y concluye su solicitud diciendo con insistencia (U) : “ $Y$ ten cuidado, eh! Hubo allá una explosión... De repente tengo miedo por Cédric y Thomas" (I) (7 :11 horas). Toma conciencia entonces de que los agentes de guardia pueden haber resultado heridos de la explosión, a punto tal de no poder responder al teléfono (R/I). Vuelve a llamar a los bomberos (U), aclarando que ahora teme una situación de vital urgencia (I).

41 Al cabo de la fase simulada, al inicio del debriefing, el agente de conducción interpela a los dos agentes de guardia : “Ni se les ocurra hacerme eso, ¿eh?!" (I), lo cual revela el eco real que tuvo para él la experiencia vivida en un contexto ficticio. Por su parte, los operarios de la célula de crisis relatan de entrada que simular la llamada telefónica a las cónyuges de los agentes ficticiamente fallecidos los desconcertó profundamente.

\subsubsection{Superación de la impasse y extensión del entendimiento}

Analizamos aquí el comportamiento del agente de conducción frente a la perturbación inducida por el suceso "fuera del entendimiento" vivido (imposibilidad de comunicarse con el guardia), con el fin de extraer de allí las oportunidades de desarrollo que propician los ámbitos de escenificación de lo "inesperado" y lo "impensado".

El agente de conducción manifiesta un alto grado de estrés y confusión cuando intenta contactar por teléfono, en cuatro oportunidades, a los dos agentes de guardia (en vano). Este episodio es una buena ilustración de la necesaria distinción que ha de efectuarse entre disponer de los saberes necesarios para la interpretación y la acción eficaz y producir significaciones que aseguren una inteligibilidad de los acontecimientos. En efecto, el agente de conducción sabe obviamente (i) que ha habido una explosión y (ii) que los agentes de campo son vulnerables a las explosiones, por lo que dispone de todos los saberes necesarios; sin embargo, resulta incapaz en ese momento de producir una interpretación verosímil, lo cual lo paraliza.

Esa perturbación lleva así al agente de conducción sucesivamente: (i) a un estado inicial de desasosiego, de "desplome" de la semiosis y de parálisis; (ii) a aceptar su estado de incertidumbre y a buscar nuevos recursos y nuevos medios para alcanzar su objetivo, aunque eso implique alejarse del procedimiento; y (iii) a formular varias hipótesis por abducción, invalidadas por la acción, antes de alcanzar una hipótesis que le permita provisoriamente salir de la impasse (y que resultará estar en sintonía con el guion).

A partir de inferencias teóricas, podemos pensar que este episodio contiene las siguientes oportunidades de aprendizaje-desarrollo:

Campo de lo "inesperado" (entrada de los acontecimientos en la estructura de expectativas del agente):

- Prefiguración de un supuesto plausible (p. ej., una explosión), el cual, podemos pensar, generará menos sorpresa en el agente en situación de accidente real.

- Beneficio de un conjunto de experiencias de percepción y significaciones (surgimiento de emociones, indicios, puntos de referencia, recursos) ligadas a ese supuesto, las cuales, 
podemos pensar, incrementarán la capacidad del agente para producir significaciones en situación de accidente real y, por tanto, su grado de reactividad.

- Prefiguración de una solución sustentable (p. ej., que un tercer agente despeje la duda), la cual, por ser prefigurada, será más propensa a reconfigurarse de manera semejante en situación de accidente real. situaciones difíciles o traumáticas (transformadas en ficción por los actores) dan lugar a experiencias reales, que marcan a los individuos implicados de manera potencialmente duradera, haciéndoles descubrir, interpretar y actuar en situaciones aún "impensadas" e "inexperimentadas". posibilitan permite provocar el advenimiento de situaciones cuyo carácter infrecuente (episodios dramáticos actualizados en el TdV, episodios de crisis anticipados en el ejercicio) convierte en incierta y difícil su aprehensión. Pero provocar su advenimiento 
en el campo de la experiencia de los y las participantes de forma idéntica a lo que fueron o podrían ser, no sólo no sería formador, sino que sería potencialmente deletéreo. El potencial de formación radica en una mediación de la experiencia-meta (artística en lo que atañe al TdV, lúdica $\left.{ }^{[1]}\right]$ en cuanto al ejercicio de crisis), que a su vez le confiera un carácter de familiaridad (necesaria para la obtención del efecto mimético entre formación y vida cotidiana), de extrañeza (necesaria para la obtención de una investigación / un sondeo por parte de los y las participantes) y de seguridad (necesaria para un compromiso auténtico por parte de los y las participantes). Esto permite que los y las participantes experimenten de modo relativamente controlado "cómo puede ser", "qué puede provocar", "qué puede querer decir" (verse confrontado de nuevo, en circunstancias distintas, a un suceso crítico vivido -en el TdV-, o bien verse confrontado por primera vez a un acontecimiento crítico posible -en el ejercicio de crisis). Tales condiciones son muy favorables para el surgimiento de un proceso abductivo.

La actividad de los y las participantes en el TdV y en el ejercicio de crisis comparten una característica que Horcik, Savoldelli, Poizat, \& Durand (2014) definen como una "doble intencionalidad". En efecto, la dimensión ficcional presente en estos dos dispositivos genera o revela en los y las participantes compromisos encastrados y orientados -sea simultánea o alternativamente- hacia el desafío de la formación (que la investigación / el sondeo escenificada llegue a buen puerto) y hacia el desafío centrado en la vida ordinaria (sobrepasar un impasse). El TdV se asemeja al teatro (escritura y actuación de una obra) pero sin serlo (la finalidad y el direccionamiento son muy diferentes del teatro común). El ejercicio de crisis se asemeja a una gestión de crisis (acontecimientos, procedimientos, estrés, etc.) pero sin serlo (siempre se sabe que se trata de una simulación y que los errores no tendrán un impacto real en la seguridad). Los citados autores y autoras conceptualizan la experiencia correspondiente a esa "doble intencionalidad" como una "doble negación" : el TdV no es teatro, pero no es no teatro; el ejercicio de crisis no es una gestión de crisis pero no es una no gestión de crisis. La vivencia que acompaña esa tonalidad de compromiso ficcional se estima particularmente prometedora para tender puentes entre formación y vida ordinaria (Durand, 2008).

\subsection{Dimensión “eventual”}

54 Un evento es una occurrencia que rompe el curso de la vida ordinaria. No se trata simplemente de una circunstancia que cobra sentido "en sí", sino de un hecho aprehendido como imprevisible en el flujo de lo cotidiano. Es una discontinuidad que, al tiempo que es inmanente a una situación, suspende el tiempo y marca una pausa entre pasado y futuro, abriendo una brecha en las significaciones asociadas a la existencia vivida. Ese hecho se convierte en un acontecimiento en el momento en que (i) resulta muy significativo para determinado individuo -o determinada colectividad- que se siente afectado por él, (ii) no se deja comprender a partir de las significaciones previas, pero abre camino a otras significaciones posibles, (iii) no es abarcable según un orden lineal de causa-efecto (Romano, 1998) y (iv) tiende a generar un proceso de investigación tendiente a recobrar una nueva estabilidad, en el supuesto en que vaya acompañado de una considerable desestabilización del individuo. aleatorio y otro que se presenta como "rendez-vous "en el marco de una red de actores. 
El primero, el evento aleatorio, es sufrido, forma parte de los hechos "inesperados" a los cuales cabe hacer frente, y a menudo está asociado con la incertidumbre y hasta con la crisis. Tal suceso requiere ser absorbido en la existencia por una nueva configuración de las significaciones. Si tal no es el caso, se instala al respecto un cuestionamiento "que gira en falso", y ese evento representa entonces una molestia (más o menos importante), algo como una piedra en el zapato, que hace que el individuo se detenga en él y busque conferirle alguna significación singular.

El evento "rendez-vous" remite a la intención y al deseo de una realización futura en el marco de una red de actores compuesta, en los dos casos arriba descritos, por los formadores y las formadoras comprometidos/as en ambos dispositivos de formación. Aunque anticipada, la realización de ese suceso siempre es más o menos incierta, y su predicción total y minuciosa resulta imposible. La vivencia del evento "rendez-vous" es la de la proyección y la anticipación, y vale como compromiso de hacer algo. Posee un poder de transformación de las significaciones de la historia de la cual la persona (en estos casos, la o el participante) es protagonista. Este evento posee un poder de generación de cambios en las dinámicas de significación.

En el TdV, emerge una circularidad entre eventos aleatorio y "rendez-vous" (Zarifian, 1995). Al elegir sobre qué tratará la obra teatral, los y las participantes designan algo destacado, fuente de sufrimiento enquistado y de impasse incomprensible. Se constituye como evento aleatorio aquello que se extrae de la experiencia pasada y eso es elegido como referencia de la ficción teatral. La teatralización acompañada por los y las profesionales intervinientes es una promesa de evento "rendez-vous" que puede hacer brotar nuevas significaciones, "reparadoras". Se busca que las situaciones actuadas en la formación tengan para los y las participantes un "aire familiar" con las situaciones críticas, de modo tal que la formación contribuye así a una doble circulación de experiencias : entre los sucesos, cronológicamente distantes, y entre las personas presentes, que no son las mismas en la situación pasada y actual.

En el ejercicio de crisis, el movimiento se invierte : se apunta a una circularidad entre un evento "rendez-vous" (simulación en formación) anterior al aleatorio (riesgo de que sobrevenga una crisis). Esto ocurre proponiendo situaciones que perturban el binomio actor/entorno, por medio de la provocación de una experiencia crítica controlada. Para hacerlo, es necesario por una parte dosificar el carácter crítico de la perturbación, por otra, ofrecer otros posibles a través de la proscripción, según el principio : "todo lo que no está prohibido está permitido”. Por lo demás, la superación de la situación crítica, convertida a su vez en un acontecimiento aleatorio (para los y las participantes), es posible a través del acompañamiento en de un "desapego analítico" posterior al evento. Lo anterior va más allá del tradicional debriefing (brecha entre lo esperado y lo realizado), puede desbloquear un estado de desorientación, renuncia o ruptura y propiciar una forma de actividad sostenible y una capacidad de desarrollo y proyección hacia el futuro. Se busca así que una hipotética situación de crisis futura tenga para los y las participantes un "aire familiar" con una o varias situaciones vividas directamente -o por interpósita persona- a través de formaciones que hicieron surgir significaciones nuevas, "preparadoras". Asimismo, esto contribuye a una doble circulación de experiencias (entre los acontecimientos y las personas), pero en el sentido opuesto.

59 En ambos casos, dado que la dimensión "eventual" resulta muy propicia para los procesos abductivos, las significaciones inicialmente producidas son re-enactuadas en condiciones diferentes. Así, estas son reelaboradas según modos de refuerzo, 
debilitamiento y/o relativización que tienden a enriquecer el Referencial de los y las participantes, contemplados como "reservorios de sentido" por Weick (1993), así como la capacidad de estos para significar. Esa semiosis tiende a ayudar a los y las participantes a "reparar" un eslabón de una cadena interpretativa (en el TdV), lo cual permite vivir mejor con un episodio traumático y/o a crear nuevos eslabones (en el TdV y el ejercicio de crisis), lo cual permite recobrar/desarrollar una capacidad de proyección hacia el futuro.

La dimensión "eventual" utilizada por ambos dispositivos se despliega asimismo al nivel social, a través de las comunidades que participan, sea que tales comunidades les preexistan (comunidad de práctica y de oficio en el ejercicio de crisis) o no (generación de una comunidad mediante un compromiso fuerte y común en el TdV). En los dos casos, uno de los roles de la escenificación es constituir colectivamente un evento, es decir, dramatizar las circunstancias para que surja en los y las diferentes participantes una íntima sensación de "concernimiento" (Brunet, 2008). Esto consiste en un compromiso intencional y afectivo "de fondo" para con la investigación/sondeo y quienes la comparten, lo cual se plasma en particular en una atención sostenida hacia sí mismo y hacia los demás. La necesidad de que el colectivo tenga éxito es primordial y se traduce en el hecho de que cada uno/a "salga adelante". En el TdV, el acontecimiento colectivo emerge de dinámicas grupales ricas, unidas en el plano emocional $\mathrm{y}$, en especial, sostenidas por la puesta en común de vivencias individuales de una gran carga afectiva. La puesta en escena explota esas dinámicas para crear las condiciones de una expresión estética y de una presencia atenta para con el otro. Esos fenómenos no sólo son las premisas de la reanudación de la semiosis en el plano individual: son su vehículo.

61 En el ejercicio de crisis analizado, el acontecimiento de la muerte ficticia de los colegas de campo genera en los agentes una doble experiencia significativa de vulnerabilidad frente riesgo industrial : la propia vulnerabilidad ante lo "impensado" (al experimentar confusión y un sentimiento de impotencia en una situación que escapa a su comprensión, e inclusive a su entendimiento) ; pero también la vulnerabilidad física de los otros, colegas, amigos (al tener la experiencia ficcional de una situación posible : el accidente mortal). Tales fenómenos tienen una función de desarrollo contra-intuitiva, dado que podría pensarse que el incremento de la sensación de vulnerabilidad constituye una regresión. No obstante, participan en el desarrollo de una humildad y una vigilancia en acción, disposiciones que las ciencias de la seguridad identifican como muy favorables para la construcción continua de las condiciones de seguridad (Weick \& Sutcliffe, 2001).

\section{Contribución al programa de investigación tecnológica en materia de formación y al programa del CdA}

62 En el presente artículo, intentamos explicar que la formación, pensada según la hipótesis de la actividad-signo, en ciertos casos (en particular, los supuestos de impasse arriba descritos) puede especificar de manera ventajosa sus objetos y sus métodos a partir de la comprensión de distintos modos de perturbación y/o reanudación de la semiosis, así como de la articulación entre ambas. 
Discutimos en lo que sigue las implicaciones de un enfoque de la perturbación de la actividad en formación con miras a la reconfiguración de significaciones.

A partir de las dos formaciones analizadas, hemos descrito las oportunidades de desarrollo generadas cuando se toman en cuenta o se utilizan perturbaciones en la vivencia de los actores, frente a acontecimientos inéditos o críticos. Las dimensiones "reparadoras" y "preparadoras" ofrecen a los actores comprometidos la perspectiva tanto de resignificar como de tener que gestionar situaciones críticas consideradas como "inesperadas" y/o "impensadas". Dichas dimensiones (y los efectos asociados) están contenidas en dos componentes comunes a las formaciones estudiadas, desplegándose de manera distinta en una y otra.

5 La primera ya ha sido ampliamente descrita como un efecto de extensión del entendimiento, o "campo cognitivo experiencial" (Varela, 1996), es decir, un aumento por abducción de las significaciones posibles en el mundo propio del actor. Esto es apto (i) para permitir el desenlace del impasse frente a vivencias petrificantes y (ii) para reducir el riesgo de sorpresa, y a fortiori de estupefacción o de "desplome" de la semiosis, en situaciones que no brindan la posibilidad de movilizar y poner en relación conocimientos pertinentes y disponibles.

6 La segunda aún no ha sido descrita y se refiere a una especificidad de las disposiciones que se actualizan frente a situaciones confusas, que podemos calificar como "capacidad negativa". Esta noción, que el psicoanalista Bion toma prestada del poeta inglés John Keats, corresponde a la capacidad "de permanecer en medio de la incertidumbre, los misterios, las dudas, sin empecinarse en buscar el hecho y la razón" (Keats, 1993, p. 76). En la relación con el otro (pero más generalmente en la relación con el entorno), se trata de una disposición a "tolerar la turbulencia emocional de no saber; abstenerse de imponer soluciones falsas, omnipotentes o prematuras a un problema, una situación ambigua o una perturbación emocional" (Bion, 1991, p. 207, traducción libre).

"Esencialmente, se trata de hacer frente a la experiencia, en lugar de evitarla. [...] Como tal, [la capacidad negativa] describe la naturaleza de la búsqueda de una mentalidad [...], pensante, que va más allá de los principios didácticos conocidos y amplía la estructura de la personalidad" (Williams, 2018, p. 42, traducción libre).

68 Esa capacidad se conoce como negativa en el sentido de que cuando un individuo consigue tolerar la insuficiencia percibida de sus medios de acción y sus hábitos de pensamiento para que una situación perturbadora sea vivida de manera aceptable, abre entonces una capacidad "en creux" (en lo implícito) (Blanchard-Laville, 2013), una disponibilidad para inventar otra cosa, es decir, para la abducción. Pero esto supone para todas las personas comprometidas en las formaciones, formadores/as y participantes, (i) aceptar que sus habilidades, su motivación y su sinceridad no garantizan en absoluto el éxito del TdV o la gestión eficaz de una crisis "fuera del cuadro" y (ii) estar atentas y ser solícitas para consigo mismas, los demás y aquello que tienen que hacer juntos/as.

Por ejemplo, los y las profesionales de la educación, del cuidado y del teatro que intervienen en el $\mathrm{TdV}$ son altamente competentes. Aseguran a los y las participantes respeto y no emiten ningún juicio de valor sobre sus producciones o sobre la experiencia vivida. Es más, están un poco alejados de sus prácticas habituales : están haciendo su trabajo aunque sin hacerlo de veras. Son los garantes de un proceso de teatralización y acompañan a los y las participantes en la realización de sus obras, por 
más que la mayoría de las veces estos últimos no conozcan los códigos del teatro. Al acompañarlos deben respetar sus gustos, sus elecciones artísticas y, sobre todo, la expresión de aquello que se halla en lo más hondo de sí. A pesar de la incertidumbre de la situación, actúan según una "capacidad negativa", cuidan a los y las participantes, confiados en el potencial de desarrollo y en el impacto del proceso artístico.

En el ámbito de la seguridad industrial, el concepto de "capacidad negativa", que aún requiere ser ampliamente desarrollado en términos empíricos y conceptuales, remite en conjunto a las nociones de "mindfulness" (plena conciencia, vigilancia), "situation awareness" (conciencia / comprensión de la situación) y "sensemaking", sobre todo teorizadas en el marco de las ciencias de las organizaciones después de Weick. El interés del concepto es esencializar y desarrollar la capacidad para actuar ante lo desconocido bajo un postulado tácito de "incognoscibilidad" (Weick, 2006), es decir que el operario concibe intuitivamente que la comprensión de una situación por deducción de sus conocimientos anteriores no siempre debe preceder a la acción : en caso de gran confusión, actuar en función de puntos de referencia y procedimientos mínimos puede constituir un inicio de comprensión de la situación por abducción (emisión y test de hipótesis provisorias). Determinante para pensar la intervención frente a situaciones fuertemente indeterminadas y hasta críticas (Pettersen, 2013), a nuestro entender esta capacidad también ha de ser pensada para la formación.

71 Los efectos descritos de la extensión del entendimiento y del desarrollo de una capacidad negativa favorecen la expresión y el desarrollo de dimensiones cruciales para la gestión de situaciones de crisis, tales como la facultad de interpretación (sobrepasar la sideración, la incomprensión y aceptar actuar en medio de una fuerte incertidumbre), de imaginación (emitir y jerarquizar hipótesis explicativas sobre la base de información escasa, imprecisa, inclusive potencialmente falsa), de invención (idear nuevas modalidades de acción) y de improvisación (hallar recursos de diferente índole en un entorno que parece estar desprovisto de ellos, con miras a poder actuar). Dicho en otros términos, se trata de que un individuo desarrolle una disposición (i) a aceptar incondicionalmente su propia vulnerabilidad ante la incertidumbre, siendo que sus hábitos de pensamiento y de acción lo disponen a la inversa y (ii) a hallar medios para actuar, aun sin meta precisa, pero creando de hecho oportunidades de significación (detección de indicios), de elaboración de y de experimentación de hipótesis (búsqueda) y de inflexión de la semiosis (abducción).

Alcanzar semejantes objetivos requiere crear condiciones favorables para el despliegue de un régimen de actividad con un fuerte componente imaginario, que apele a las dimensiones abductivas e icónicas de la significación, que son muy prometedoras de desarrollo. A esto se añade la preocupación por dramatizar el desafío de la formación lo suficiente para "generar evento" en los y las participantes, garantizando al mismo tiempo el sentimiento de seguridad psicológica necesaria para un compromiso genuino de parte de ellos y ellas. Tal preocupación, por lo demás, es primordial para toda propuesta que apunte a provocar el advenimiento de lo inédito y lo crítico en la experiencia de los y las participantes de forma dramática (indirecta, metafórica, lúdica, simulada, puesta en escena, narrada, actuada, etc.). 


\section{Conclusión}

A partir de análisis de vivencias de impasse en el campo de la formación, la presente contribución permite respaldar las opciones de diseño basadas en la hipótesis de la actividad-signo y el proceso de abducción. Nuestro trabajo incita (i) a no tomar por único objeto de formación los aprendizajes-desarrollos que consisten en la construcción de saberes nuevos por parte del actor, lo cual es reductor atendiendo la diversidad de los procesos de aprendizaje-desarrollo que conviene poder generar, captar o sostener en determinados casos y (ii) a descentrarse cada vez que sea oportuno de una lógica de acumulación de saberes, en beneficio de una lógica de perturbación de la actividad, a efectos de reanudar o extender la semiosis.

A fin de cuentas, el análisis conjunto de estos dos dispositivos de formación particulares subraya el interés de las inferencias abductivas en situación de formación, con el fin de "reparar" y "preparar" para una vivencia de impasse, pero también los principios de diseño que fomentan el proceso abductivo. Sería necesario realizar estudios complementarios (i) para dar cuenta y precisar los procesos de construcción de nuevos saberes por medio de inferencias abductivas, sin descuidar la articulación con las inferencias deductivas e inductivas y (ii) con la perspectiva de testear la fecundidad empírica de las diferentes subcategorías del Interpretante propuestas en el marco semiológico del CdA (Theureau, 2015). Esas subcategorías del Interpretante por ahora son especulativas y han de ponerse a prueba en el marco de la investigación empírica, y muy particularmente, en las investigaciones en el área de la educación y la formación. Por último, futuras investigaciones deberán detallar las condiciones de surgimiento, generación y acompañamiento de abducciones mejoradoras en situaciones formativas o laborales. Tales avances contribuirían con una tecnología de formación desarrollada según la hipótesis de la actividad-signo.

\section{BIBLIOGRAFÍA}

Ahmed, S., \& Parsons, D. (2013). Abductive science inquiry using mobile devices in the classroom. Computers \& Education, 63, 62-72.

Assal, J-P., Durand, M., \& Horn, O. (2016). Le Théâtre du Vécu : Art, Soin, Éducation. Dijon : Raison et passions.

Bion, W. (1991). A Memoir of the Future (3 Vols. 1975, 1977, 1979). London : Karnac.

Blanchard-Laville, C. (2013). Accompagnement clinique et capacité négative. Cahiers de Psychologie Clinique, 41(2), 63-80.

Bopry, J. (2007). The give and take between semiotics and second-order cybernetics. Semiotica, 164, 31-51.

Brunet, P. (2008). De l'usage raisonné de la notion de “ concernement " : mobilisations locales à propos de l'industrie nucléaire. Natures sciences sociétés, 16(4), 317-325. 
Chauviré, C. (2016). Le “ nous » de Peirce ou la critique de l'égoïsme. Klēsis, 34, 116-129.

Colapietro, V., Midtgarden, T., \& Strand, T. (2005). Introduction: Peirce and education: The conflicting processes of learning and discovery. Studies in Philosophy and Education, 24(3-4), 167-177.

Cunningham, D.J. (1998). Cognition as semiosis: The role of inference. Theory and Psychology, 8 , 827-840.

Cunningham, D. J., Schreiber, J. B., \& Moss, C. M. (2005). Belief, doubt and reason : CS Peirce on education. Educational Philosophy and Theory, 37(2), 177-189.

Dieumegard, G. (2009). Connaissances et cours d'expérience vers une grammaire minimale de description dans les situations d'éducation et de formation. Revue d'anthropologie des connaissances, 3(2), 295-315.

Dieumegard, G. (2011). Dimensions cognitives et sociales dans l'étude de l'activité des élèves. La représentation comme inférence individuelle-sociale dans le cours d'expérience. Éducation et didactique, 5(5.3), 33-60.

Durand, M. (2008). Un programme de recherche technologique en formation des adultes. Éducation \& Didactique, 2(3), 97-121.

Durand, M. (2017). L'activité en transformation. In J.-M. Barbier, \& M. Durand (Eds.), Encyclopédie d'analyse des activités (pp. 47-70). Paris : PUF.

Durand, M., Goudeaux, A., Horcik, Z., Salini, D., Danielian, J., \& Frobert, L. (2013). Expérience, mimesis et apprentissage. In L. Albarello, J.-M. Barbier, E. Bourgeois, \& M. Durand (Eds.), Expérience, activité, apprentissage (pp. 39-64). Paris : PUF.

Fisette, J. (2009). L'icône, l'hypoicône et la métaphore : L'avancée dans l'hypoicône jusqu'à la frontière du non-conceptualisable. Visual Culture, 14, 7-46.

Flandin, S., Poizat, G., \& Perinet, R. (2019). Contribuer à l'amélioration de la sécurité industrielle “ par le facteur humain » : Un regard pour aider à (re)penser la formation. Collection Regards sur la sécurité industrielle. Toulouse : FONCSI.

Gallese, V. (2011). La simulation incarnée et son rôle dans l'intersubjectivité. In P. Attigui \& A. Cukier (Eds.), Les paradoxes de l'empathie (pp. 49-72). Paris : CNRS.

Genette, G. (2004). Métalepse : De la figure à la fiction. Paris : Seuil.

Grossetti, M. (2004). Sociologie de l'imprévisible. Paris : PUF.

Horcik, Z., Savoldelli, G., Poizat, G., \& Durand, M. (2014). A phenomenological approach to novice nurse anesthetists' experience during simulation-based training sessions. Simulation in Healthcare, 9(2), 94-101.

Husserl, E. (1964). Leçons pour une phénoménologie de la conscience intime du temps. Paris : PUF.

Hwang, M. Y., Hong, J. C., Ye, J. H., Wu, Y. F., Tai, K. H., \& Kiu, M. C. (2019). Practicing abductive reasoning: The correlations between cognitive factors and learning effects. Computers \& Education, $138,33-45$.

Keats, J. (1993). Lettres. Paris : Belin.

Maturana, H., \& Varela, F. J. (1994). L'arbre de la connaissance. Paris: Addison-Wesley.

Midtgarden, T. (2005). On The Prospects of A Semiotic Theory of Learning. Educational Philosophy and Theory, 37(2), 239-252. https://doi.org/10.1111/j.1469-5812.2005.00112.x 
Midtgarden, T. (2010). Toward a Semiotic Theory of Learning. Semiotics Education Experience, 71-82. https://doi.org/10.1163/9789460912252_006

Oh, P. S. (2008). Adopting the abductive inquiry model (AIM) into undergraduate earth science laboratories. In Science education in the 21st century (pp. 263-277). Nova Science.

Oh, P. S. (2011). Characteristics of abductive inquiry in earth science : An undergraduate case study. Science Education, 95(3), 409-430. https://doi.org/10.1002/sce.20424

Paavola, S., \& Hakkarainen, K. (2005). Three Abductive Solutions to the Meno Paradox - with Instinct, Inference, and Distributed Cognition. Studies in Philosophy and Education, 24(3), 235-253. https://doi.org/10.1007/s11217-005-3846-Z

Peirce, C. S. (1868). Some consequences of four incapacities. Journal of Speculative Philosophy, 2, 140-157.

Peirce, C.S. (1994). The collected paper of Charles Sanders Peirce (Volumes I-VIII). Charlottesville: Intelex.

Pettersen, K. (2013). Acknowledging the role of abductive thinking: A way out of proceduralization for safety management and oversight? In C. Bieder \& M. Bourrier (Eds.), Trapping Safety into Rules (pp. 107-117). Farnham : Ashgate.

Poizat, G., \& Durand, M. (2015). Analyse de l'activité humaine et éducation des adultes : faits et valeurs dans un programme de recherche finalisée, Revue française de pédagogie, 190, 52-60.

Poizat, G., Durand, M., \& Theureau, J. (2016). Challenges of activity analysis oriented towards professional training. Le Travail Humain, 79, 233-258.

Poizat, G. \& Flandin, S. (accepté). Analyse de l'activité et formation: Vers un idéal de programme de recherche technologique. Toulouse : Octarès.

Poizat, G., \& Goudeaux, A. (2014). Appropriation et individuation : un nouveau modèle pour penser l'éducation et la formation? TransFormations : Recherches en éducation et formation des adultes, 12, 13-38.

Poizat, G., Salini, D., \& Durand, M. (2013). Approche énactive de l'activité humaine, simplexité, et conception de formations professionnelles. Education Sciences \& Society, 4, 97-112.

Récopé, M., Fache, H., Beaujouan, J., Coutarel, F., \& Rix-Lièvre, G. (2019). A study of the individual activity of professional volleyball players: Situation assessment and sensemaking under time pressure. Applied ergonomics, 80, 226-237.

Rosch, E. (1973). On the internal structure of perceptual and semantic categories. In T. Moore (Ed.), Cognitive development and acquisition of language (pp. 111-144). New York : Academic Press.

Rosenthal, V. (2012). La voix de l'intérieur. Intellectica, 58(2), 53-89.

Romano, C. (1998). L'événement et le monde. Paris : PUF

Salini, D. (2013). Inattendus et transformations de signification dans les situations d'information-conseil pour la validation des acquis de l'expérience. Thèse non publiée pour le doctorat en sciences de l'éducation, Université de Genève.

Salini, D., \& Durand, M. (2016). Événement dramatique et éducation événementielle, in J-P. Assal, M. Durand, \& O. Horn (Eds.), Le Théâtre du Vécu : Art, Soin, Éducation (pp. 265-276). Dijon: Raison et passions.

Salini, D., \& Durand, M. (2020). Overcoming a lived experience of personal collapse by creating a theatrical drama: an example of developmental and resilient adult education. In L. McKay, G. 
Barton, S. Garvis, \& V. Sappa (Eds.), Arts-based research, resilience and wellbeing across the lifespan (pp. 169-189). Interdisciplinary handbook. Melbourne : Palgrave Macmillan.

Salini, D., \& Poizat, G. (sous presse). Dénouements possibles de l'expérience d'impasse : pistes de compréhension et perspectives développementales. Orientation scolaire et professionnelle. Dossier: L'expérience dans les pratiques d'accompagnement et de conseil en formation d'adultes.

Schütz, A. (1987) Le chercheur et le quotidien : Phénoménologie des sciences sociales. Paris : Méridiens Klincksieck.

Simondon, G. (2005). L'individuation à la lumière des notions de forme et d'information. Grenoble: Millon.

Stables, A., \& Gough, S. (2006). Toward a semiotic theory of choice and of learning. Educational Theory, 56(3), 271-285.

Stiegler, B. (2010). Ce qui fait que la vie vaut la peine d'être vécue : De la pharmacologie. Paris:

Flammarion.

Theureau, J. (2006). Le cours d'action: Méthode développée. Toulouse : Octarès.

Theureau, J. (2009). Le cours d'action : Méthode réfléchie. Toulouse : Octarès.

Theureau, J. (2010). Les entretiens d'autoconfrontation et de remise en situation par les traces matérielles et le programme de recherche " cours d'action ». Revue d'anthropologie des connaissances, 4(2), 287-322.

Theureau, J. (2015). Le cours d'action : L'enaction et l'expérience. Toulouse: Octarès

Varela, F. (1996). Neurophenomenology: A methodological remedy for the hard problem. Journal of Consciousness Studies, 3(4), 330-349.

Ventimiglia, M. (2005). Three Educational Orientations : A Peircean Perspective on Education and the Growth of the Self. Studies in Philosophy and Education, 24(3-4), 291-308. https://doi.org/ $10.1007 / \mathrm{s} 11217-005-3851-2$

Violi, P. (2014). Paesaggi della memoria: Il trauma, lo spazio, la storia. Torino: Bompiani.

Weick, K. (1993). The collapse of sensemaking: The Mann Gulch disaster. Administrative Science Quarterly, 38(4), 62.

Weick, K. (2006). Faith, evidence, and action: Better guesses in an unknowable world. Organization studies, 27(11), 1723-1736.

Weick, K., \& Sutcliffe, K. (2001). Managing the unexpected: Assuring high performance in an age of complexity. San Francisco: Jossey-Bass.

Williams, M. (2018). The aesthetic development: The poetic spirit of psychoanalysis - Essays on Bion, Meltzer, Keats ( $2^{\text {nd }}$ ed.). Abingdon : Routledge.

Zarifian, P. (1995). Le travail et l'événement. Paris : L'Harmattan.

\section{NOTAS}

1. En proceso de edición, ese trabajo constituirá una nueva escala "recapitulativa" del programa.

2. Esta duplicación de términos se debe a que acercamos dos tradiciones de investigación: una procedente de la psicología, que ha adoptado las nociones de "tipicalización" y "prototipo" (Rosch, 1973), la otra nos viene de la sociología, que ha adoptado las nociones de "tipificación" y “tipo" (Schütz, 1987). En adelante, emplearemos los vocablos "tipicalización" y "tipo", lo cual 
simplifica la lectura sin plantear ningún problema teórico, creemos, teniendo en cuenta el nivel de generalidad de la argumentación.

3. En el sentido de que no es reductible a acciones entre pares.

4. Véase asimismo el artículo introductorio a este dossier especial.

5. Siempre y cuando se considere que "surgimiento de significación" en el sentido de Varela y "sensemaking" en el sentido de Weick son asimilables, lo cual no está comprobado y requeriría trabajos comparativos (Récopé, Fache, Beaujouan, Coutarel, \& Rix-Lièvre, 2019).

6. Como cada taller de TdV dura alrededor de 24 horas, no se podía mostrar a los participantes la totalidad de las grabaciones. Así, se constituyeron fragmentos de aproximadamente una hora, específicos para cada uno, en referencia a las etapas fundamentales del propio taller.

7. Aquí y en el estudio siguiente, los nombres han sido cambiados.

8. El término empleado por Pierce en inglès "musement", traducido al francés como "musarde", significando a la vez "meditar, ponderar, estar absorto en los pensamientos" no tiene directa correspondencia en castellano.Proponemos por lo tanto esta traducción que se aproxima.

9. Para más información relativa al proyecto FOResilience: https://www.unige.ch/fapse/craft/ recherche/passees/foresilience/

10. Las indicaciones horarias son los momentos del ejercicio en los cuales se produjeron tales verbalizaciones.

11. La mediación es lúdica en el sentido de que en un ejercicio (y en una simulación en general), los y las participantes actúan haciendo "como si"; no es lúdica en el sentido de que el ejercicio sea divertido

\section{RESÚMENES}

Nuestra investigación considera las formaciones como ocasiones de perturbación y/o reanudación de la dinámica de significación de los y las participantes. La presente contribución tiene por objeto (i) producir un avance en la conceptualización de las formaciones, concebidas como ayudas a los y las participantes para comprender y transformar su actividad y (ii) elaborar principios de diseño transversales que permitan implementar tales formaciones en diferentes contextos. Nos basamos en el análisis de las formaciones que apuntan ya sea a la gestión, ya sea a la superación de eventos vividos como inéditos y críticos por los individuos en cuestión. Los principios de diseño de tales formaciones y sus efectos son analizados con la ayuda de herramientas conceptuales del curso de acción, incorporando dos dimensiones suplementarias : ficcional y "eventual”. La contribución del presente artículo al programa curso de acción y a la investigación en materia de formación es discutida en la parte final, bajo el prisma de la hipótesis de la actividad-signo.

A nossa investigação encara os cursos de formação como oportunidades para perturbar e/ou reenergizar a dinâmica de significado para os participantes. Os objetivos desta contribuição são (i) fazer avançar a conceptualização das formações concebidas como ajudas para os participantes na compreensão e transformação da sua atividade, e (ii) desenvolver princípios transversais de conceção que permitam a implementação destas formações em diferentes contextos. Contamos com a análise dos cursos de formação destinados a gerir ou superar acontecimentos experimentados como novos e críticos pelos indivíduos em causa. Os princípios de conceção destas formações e os seus efeitos são analisados utilizando as ferramentas conceptuais do curso 
de ação, integrando duas dimensões adicionais : ficcional e baseada em eventos. A contribuição para o programa do curso de ação e para a investigação em formação é discutida no final do artigo através do prisma da hipótese da atividade-sinal.

Notre recherche pense les formations comme des occasions de perturbation et/ou relance de la dynamique de signification des participant-es. Cette contribution a pour buts (i) de faire avancer la conceptualisation de formations conçues comme des aides aux participant-es pour la compréhension et la transformation de leur activité, et (ii) d'élaborer des principes de conception transversaux qui permettent la mise en œuvre de ces formations dans différents contextes. Nous nous appuyons sur l'analyse de formations visant soit la gestion, soit le dépassement d'évènements vécus comme inédits et critiques par les individus concernés. Les principes de conception de ces formations et leurs effets sont analysés à l'aide des outils conceptuels du cours d'action, en intégrant deux dimensions supplémentaires : fictionnelle et événementielle. La contribution au programme du cours d'action et à la recherche en formation est discutée en fin d'article au prisme de l'hypothèse d'activité-signe.

In this research, training situations are thought as opportunities to perturb/relaunch the participants' dynamics of meaning. Our contribution aims to (i) improve the conceptualization of training situations that are thought as aids to the understanding and transformation of the participants situations, and (ii) derive cross-cutting design principles that allow the enactment of these training situations in different contexts. We rely on the analysis of training programs aiming at either the management or the overcoming of events experienced as unprecedented and critical by the individuals at stake. The design principles of these training programs and their effects are analyzed with the conceptual tools developed within the course-of-action, integrating two additional dimensions: fictional and event-driven. The contribution to course-ofaction program and to research on adult education is discussed through the perspective of the hypothesis of activity-sign.

\section{ÍNDICE}

Mots-clés: formation, activité-signe, abduction, impasse, programme de recherche technologique

Palavras-chave: formação, atividade-sinal, abdução, impasse, programa de investigação tecnológica

Palabras claves: formación, actividad-signo, abducción, impasse, programa de investigación tecnológica

Keywords: training, activity-sign, abduction, impasse, technological research program

\section{AUTORES}

\section{SIMON FLANDIN}

Université de Genève, UniMail, $40 \mathrm{Bd}$ du Pont d'Arve, 1205 Genève, Suisse

Simon.flandin@unige.ch

\section{DELI SALINI}

Istituto Universitario Federale per la Formazione Professionale (IUFFP), Via Besso 84/86, 6900

Lugano, Suisse

Deli.Salini@iuffp.swiss 


\section{ARTEMIS DRAKOS}

Université de Genève, UniMail, $40 \mathrm{Bd}$ du Pont d'Arve, 1205 Genève, Suisse

Artemis.drakos@gmail.com

\section{GERMAIN POIZAT}

Université de Genève, UniMail, $40 \mathrm{Bd}$ du Pont d'Arve, 1205 Genève, Suisse

Germain.poizat@unige.ch 